\title{
Comparative studies on the degradation of guanidino and ureido compounds by Pseudomonas
}

\author{
Catherine Tricot, ${ }^{1}$ ANDré Piérard ${ }^{1,2}$ and Victor Stalon ${ }^{1 *}$ \\ ${ }^{1}$ Laboratoire de Microbiologie, Faculté des Sciences, Université Libre de Bruxelles and ${ }^{2}$ Institut de Recherches du \\ CERIA, 1 avenue E. Gryson, B-1070 Bruxelles, Belgium
}

(Received 30 April 1990; revised 27 July 1990; accepted 2 August 1990)

\begin{abstract}
The utilization of guanidino and ureido compounds was studied in several Pseudomonas species. Multiple routes of agmatine catabolism were found. All members of the homology group I of Pseudomonas use the initial deamination of agmatine to carbamoylputrescine which is subsequently converted to putrescine. In Pseudomonas indigofera, the catabolism of agmatine can also occur via an initial hydrolysis of the amidino group to putrescine catalyzed by an agmatine amidinohydrolase. A third pathway was found in Pseudomonas cepacia, namely oxidative deamination producing guanidinobutyraldehyde catalyzed by agmatine dehydrogenase, followed by formation of guanidinobutyrate and removal of urea by guanidinobutyrate amidinohydrolase to produce 4-aminobutyrate. Novel amidinohydrolases were characterized in $\boldsymbol{P}$. putida for the utilization of arcaine and audouine, and in $\boldsymbol{P}$. cepacia for arcaine, homoarginine and guanidinovalerate. Guanidinovalerate amidinohydrolase was also detected in $P$. doudoroffii. Some of these amidinohydrolases accept more than one substrate, e.g. guanidinobutyrate and guanidinovalerate utilization by $P$. doudoroffii and $P$. cepacia, the catabolism of arcaine and audouine by $P$. putida, and the degradation of arcaine and homoarginine by $P$. cepacia.
\end{abstract}

\section{Introduction}

Pseudomonas, a bacterial genus common in soil and water, displays a great versatility in terms of the organic compounds which can serve as sole source of energy, carbon and nitrogen. The spectrum of usable compounds is a characteristic feature of each Pseudomonas species. Moreover, in a single species, several pathways may contribute to the catabolism of a specific substrate. For example, the degradation of arginine in Pseudomonas aeruginosa and Pseudomonas putida proceeds via four different pathways (Stalon \& Mercenier, 1984; Stalon et al., 1987; Jann et al., 1988).

Guanidino and ureido compounds are widespread in fungi, plants and animals. A large number of these compounds can serve as growth substrates for various Pseudomonas spp. A previous study (Stalon \& Mercenier, 1984; see also Cunin et al., 1986) has shown that the genus Pseudomonas is heterogeneous with respect to the pathways used for the breakdown of arginine. Here we extend this study to guanidino and ureido compounds in general to evaluate the capacity of Pseudomonas to utilize

Abbreviations: INT, iodonitrotetrazolium chloride; PMS, phenazine methosulphate; HEV, high voltage paper electrophoresis. these naturally occurring compounds and to determine possible variations in the usage of pathways.

\section{Methods}

Bacterial strains, media and growth conditions. The bacterial strains from our culture collection used in this work are listed in Table 1. We also included $P$. aeruginosa PAO obtained from Holloway (1955), $P$. acidovorans IP60-18 received from the Institut Pasteur (Paris, France), P. putida IRC204 from our strain collection (Stalon et al., 1967) and the Pseudomonas species P1855-344 received from Y. Dessaux, Institut des Sciences, Végétales, Gif sur Yvette, France, selected for its ability to use the guanidino compound octopine. They were routinely grown at $30^{\circ} \mathrm{C}$ except for $P$. aeruginos $a$ which was cultivated at $37 .^{\circ} \mathrm{C}$. Nitrogenfree minimal medium 154 was used (Stalon et al., 1967). Substrates used as carbon and/or nitrogen source were added after separate sterilization by filtration. When used as a carbon source, the final concentration of allantoine, allantoic acid, oxalurate, creatinine, creatine and sarcosine was $40 \mathrm{~mm}$. Other carbon sources were tested at $20 \mathrm{~mm}$. When used as a nitrogen source, substrates were usually included at a final concentration of $10 \mathrm{mM}$ (on a nitrogen content basis) in the presence of $20 \mathrm{mM}$ succinate or citrate. Bacteria were grown in liquid media as previously described (Stalon et al., 1987). The test-tubes were screened after $24 \mathrm{~h}$ and examined again after $48 \mathrm{~h}$. When the results were difficult to interpret for slowly growing cultures, the incubation period was prolonged for a further $48 \mathrm{~h}$. For enzyme activity determinations, cultures were grown aerobically as $100 \mathrm{ml}$ batches in 1 litre flasks on a rotatory shaker. Cells from exponentially growing cultures were harvested by centrifugation, washed with $\mathrm{NaCl}(0.9 \%)$ and, unless used 
Table 1. Utilization of ureido and guanidino compounds by Pseudomonas

-, No growth; NT, not tested. $\mathrm{CN}$, Utilization as carbon and nitrogen source; $\mathrm{N}$, utilization as nitrogen source only. $\mathrm{CN}$ italicized $(C N)$, means that $1 \mathrm{~mol}$ of urea was excreted per mol of substrate consumed; $\mathrm{CN}$ printed in bold type (CN), means that 2 mol of urea were produced per mol of substrate consumed. Substrates tested as a carbon source and used by none of the strains were diguanidinopropane, $N$-methylhydantoine, guanidinocaproate, guanidinosuccinate, carbamoylglutamate, hydantoïc acid, methylguanidine and barbituric acid. Substrates used as the only nitrogen source by all strains were urea, carbamoylaspartate and parabamic acid. Substrates used as the sole carbon and nitrogen source by all strains were 4-aminobutyrate, putrescine (except for $P$. acidovorans).

\begin{tabular}{|c|c|c|c|c|c|c|c|c|c|c|c|c|}
\hline & 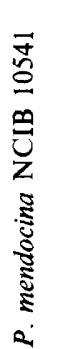 & 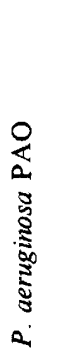 & 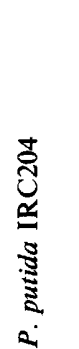 & 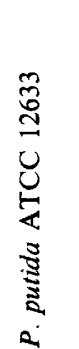 & 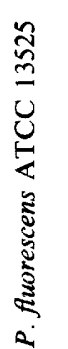 & 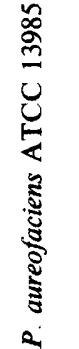 & 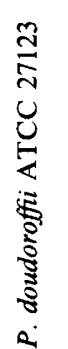 & 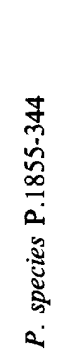 & 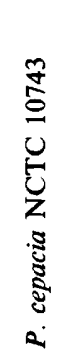 & 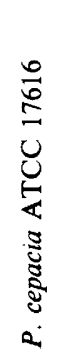 & 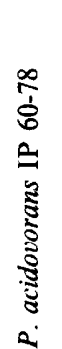 & 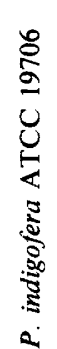 \\
\hline $\begin{array}{l}\text { Classification* } \\
\text { Growth medium }\end{array}$ & Ia & $\mathrm{Ib}$ & Ib & Ib & $\mathrm{Ib}$ & $\mathrm{Ib}$ & $\mathrm{I} \|$ & $\mathbf{I} \|$ & II & II & III & $\mathrm{U}$ \\
\hline L-Arginine & $\mathrm{CN}$ & $\mathrm{CN}$ & $C N \ddagger$ & $C N \ddagger$ & $\mathrm{CN}$ & $\mathrm{CN}$ & $\mathrm{CN}$ & $\mathrm{CN}$ & $\mathrm{CN}$ & $\mathrm{CN}$ & $\mathbf{N}$ & $\mathrm{CN}$ \\
\hline 2-Oxoarginine & $C N$ & $C N$ & $C N$ & $C N$ & $C N$ & $C N$ & $C N$ & $C N$ & $C N$ & $C N$ & $\mathbf{N}$ & $\mathbf{N}$ \\
\hline Agmatine & $\mathrm{CN}$ & $\mathrm{CN}$ & $\mathrm{CN}$ & $\mathrm{CN}$ & $\mathrm{CN}$ & $\mathrm{CN}$ & $\mathrm{CN}$ & $\mathrm{CN}$ & $C N$ & $C N$ & - & $C N$ \\
\hline Succinylagmatine & - & - & - & - & $\mathbf{N}$ & - & - & - & $C N$ & - & - & - \\
\hline Guanidinovalerate & - & - & $C N \S$ & N§ & - & N\$ & $C N$ & $C N$ & $C N$ & $C N$ & $C N$ & - \\
\hline Guanidinobutyrate & $C N$ & $C N$ & $C N$ & $C N$ & $C N$ & $C N$ & $C N$ & $C N$ & $C N$ & $C N$ & $C N$ & - \\
\hline Guanidinopropionate & - & $C N$ & - & - & - & - & - & - & - & - & - & - \\
\hline Guanidinoacetate & - & - & $C N$ & $C N$ & - & - & $C N$ & - & - & - & - & - \\
\hline Homoarginine & - & $\mathbf{N}$ & $\mathbf{N}$ & $\mathbf{N}$ & - & - & - & - & $C N$ & - & - & - \\
\hline Arcaine & $\mathbf{N}$ & $C N$ & $C N$ & $C N$ & $\mathbf{N}$ & $\mathbf{N}$ & $\mathbf{N}$ & - & $\mathbf{C N}$ & $\mathbf{C N}$ & - & $\mathbf{N}$ \\
\hline Audouine $\dagger$ & - & - & $\mathbf{C N}$ & - & - & - & - & - & - & - & - & - \\
\hline Allantoine & $\mathbf{C N}$ & $\mathbf{C N}$ & $\mathbf{C N}$ & $\mathbf{C N}$ & $\mathbf{C N}$ & $\mathbf{C N}$ & $\mathbf{C N}$ & $\mathbf{C N}$ & $\mathbf{C N}$ & $\mathbf{C N}$ & $\mathbf{N}$ & - \\
\hline Allantoic acid & $\mathbf{C N}$ & CN & CN & CN & $\mathbf{C N}$ & $\mathbf{C N}$ & $\mathbf{C N}$ & $\mathbf{C N}$ & $\mathbf{C N}$ & CN & $C N$ & - \\
\hline Creatinine & $\mathbf{N}$ & - & $\mathbf{N}$ & $\mathbf{N}$ & - & $\mathbf{N}$ & $C N$ & - & NT & NT & - & - \\
\hline Creatine & $\mathbf{N}$ & - & $C N_{\ddagger}^{\ddagger}$ & $C N_{\ddagger}^{\ddagger}$ & - & $\mathbf{N}$ & $C N$ & - & - & - & - & - \\
\hline Citrulline & $\mathbf{N}$ & $\mathbf{N}$ & $\mathrm{CN}$ & $\mathrm{CN}^{\circ}$ & $\mathbf{N}$ & $\mathbf{N}$ & $\mathbf{N}$ & $\mathbf{N}$ & $\mathrm{CN}$ & $\mathbf{N}$ & $\mathbf{N}$ & $\mathbf{N}$ \\
\hline Carbamoylputrescine & $\mathrm{CN}$ & $\mathrm{CN}$ & $\mathrm{CN}$ & $\mathrm{CN}$ & $\mathrm{CN}$ & $\mathbf{N}$ & $\mathrm{CN}$ & $\mathrm{CN} \S$ & $\mathrm{CN} \S$ & - & - & - \\
\hline Carbamoylalanine & - & - & - & - & $\mathbf{N}$ & $\mathbf{N}$ & - & - & $\mathrm{CN}$ & - & $\mathbf{N}$ & - \\
\hline
\end{tabular}

* Taxonomic classification according to Palleroni et al. (1974).

$\uparrow$ Substrate tested only as carbon source due to the presence of trace contamination by cadaverine.

$\ddagger$ Abundant urea excretion but not in the ratio $1: 1$ or $2: 1$ to substrate consumed.

$\S$ Poor growth even after $7 \mathrm{~d}$ culture.

|| Tentatively classified in group I Pseudomonas on basis of nutritional spectrum and enzymes content (see results).

immediately, were frozen as a pellet. Cell extracts were prepared at 0 $4{ }^{\circ} \mathrm{C}$ by sonication of exponential phase cells in $20 \mathrm{~mm}$-potassium phosphate buffer, pH 7.5 (Stalon \& Mercenier, 1984). Cell debris was removed by centrifugation at $20000 \mathrm{~g}$ for $20 \mathrm{~min}$. Extracts were kept at $4{ }^{\circ} \mathrm{C}$.

Protein concentrations were determined by the Lowry method. Enzymes were assayed at their $\mathrm{pH}$ optimum and in the region of proportionality between initial reaction velocity and protein concentration. Michaelis constants were determined using plots of $v^{-1}$ versus $s^{-1}$ and $s / v$ versus $s$.

Enzyme assays. All enzymes were assayed at $30^{\circ} \mathrm{C}$ except for $P$. aeruginosa enzyme activities which were assayed at $37^{\circ} \mathrm{C}$. One unit of activity is defined as the amount of enzyme catalysing the formation of $1 \mu \mathrm{mol}$ of product $\mathrm{h}^{-1}$.

Amidinohydrolase assay. The method for determining amidinohydrolase is based on the rate of urea formation during hydrolysis of the guanidino compounds. In all cases, the assay mixture contained, in
$2.0 \mathrm{ml}, 200 \mu \mathrm{mol}$ glycine/ $\mathrm{NaOH}$ buffer, $\mathrm{pH} 9.5, \mathrm{MnCl}_{2}$, substrate and cell extract. For the determination of $P$. cepacia guanidinobutyrate and guanidinovalerate amidinohydrolases, $0.4 \mu \mathrm{mol} \mathrm{MnCl}_{2}$ was used whereas $4 \mu \mathrm{mol} \mathrm{MnCl}_{2}$ were used in all other amidinohydrolase assays. The assay contained $40 \mu \mathrm{mol}$ guanidinobutyrate, guanidinovalerate, guanidinopropionate or agmatine and $20 \mu \mathrm{mol}$ arcaine, audouine or guanidinoacetate.

The reaction was initiated by adding the substrate and stopped after $10-30 \mathrm{~min}$ by addition of $2.0 \mathrm{ml} 1 \mathrm{M}-\mathrm{HCl}$. Urea was measured by the method of Archibald (1944). In every case it was verified that the reaction was linear with time and enzyme concentration. Creatine amidinohydrolase (EC 3.5.3.3) was assayed in the presence of $100 \mathrm{~mm}$-Tris/malate buffer, $\mathrm{pH} 8.0$, and $25 \mathrm{~mm}$-creatine. Agmatine deiminase (EC 3.5.3.12) was assayed under the conditions given by Mercenier et al. (1980), but with $20 \mathrm{mM}$-agmatine instead of $10 \mathrm{~mm}$.

Agmatine dehydrogenase assay. [Agmatine (acceptor) oxidoreductase deaminating EC 1.4.99.-.] The assay mixture contained, in a final volume of $1 \mathrm{ml}, 20 \mu \mathrm{mol}$ agmatine, $10 \mu \mathrm{mol} \mathrm{KCN}, 0.8 \mu \mathrm{mol}$ iodonitro- 
tetrazolium chloride (INT), $0.8 \mu \mathrm{mol}$ phenazine methosulphate (PMS) and the enzyme. The reaction was initiated by addition of the substrate and the rate of increase in absorbance at $500 \mathrm{~nm}$ was followed on a Philips recording spectrophotometer against a blank in which agmatine was omitted. An absorption coefficient of $11.5 \mathrm{mM} \mathrm{cm}^{-1}$ for reduced INT was used for the calculation of reaction rates (Meile \& Leisinger, 1982).

Analytical methods. Guanidinoderivatives in culture media were determined by the method of Micklus \& Stein (1973); allantoine and allantoic acid were assayed according to Trijbels \& Vogels (1966b); creatine was measured by the $\alpha$-naphthol diacetyl method of Ennor \& Atoken (1948); urea was determined using the method of Archibald (1944) and carbamoylderivatives according to Archibald (1944) or Prescott \& Jones (1969).

Chemicals. L-Arginine, 4-guanidinobutyrate, 3-guanidinopropionate, guanidinosuccinate, guanidinoacetate, allantoine, allantoic acid, parabanic acid, carbamoylaspartate, carbamoylglutamate, carbamoylalanine, citrulline, creatinine, creatine, sarcosine, 5-aminovalerate, cadaverine, putrescine, 4-aminobutyrate were from Sigma; agmatine, homoarginine and 6-aminocaproate were from Aldrich. Carbamoylputrescine was prepared according to Mercenier et al. (1980); 2-oxoarginine was synthesized as described previously (Stalon \& Mercenier, 1984).

Arcaine, audouine, guanidinovalerate and guanidinocaproate were synthesized by guanidinylation of agmatine, cadaverine, 5-aminovalerate and 6-aminocaproate respectively, with $O$-methylisourea. The aminoproduct $(100 \mu \mathrm{mol})$ was dissolved in $20 \mathrm{ml}$ of water adjusted to $\mathrm{pH} 10$ with $\mathrm{KOH}$. The $O$-methylisourea was added in the ratio of $1 \mathrm{~mol}$ per mol of free aminogroup. The reaction proceeded for $2-3 \mathrm{~h}$ and the $\mathrm{pH}$ was maintained at 10 by addition of $\mathrm{KOH}$. The synthesis of the guanidino compound was followed by determination of the guanidino group according to Micklus \& Stein (1973). The precipitates formed were collected by filtration and washed twice with $25 \mathrm{ml}$ of ice-cold water. They were then dried and stored at room temperature. Guanidinovalerate, which does not precipitate, was at least $98 \%$ pure and was found to contain $2 \%$ urea and traces of 5 -aminovalerate. The solution was stored at $-20^{\circ} \mathrm{C}$ after acidification to $\mathrm{pH} 8 \cdot 0$.

High voltage paper electrophoresis. Synthesized guanidino compounds and products excreted by cells growing at the expense of guanidino and amino compounds were analysed using high voltage paper electrophoresis (HEV). A detailed description of this method was presented in a previous communication (Vander Wauven \& Stalon, 1985).

\section{Results}

All the strains in this study utilize arginine as the sole energy, carbon and nitrogen source, except for $P$. acidovorans, chosen as a representative of group III Pseudomonas as defined by Palleroni et al. (1974). We have studied the ability of these strains to use guanidino and ureido compounds and tried to identify the enzymic pathways involved in their utilization.

Whereas 2-oxoarginine, guanidinobutyrate, agmatine, allantoic acid and carbamoylputrescine were used by most of the strains, the utilization of some of the guanidino compounds, as the sole carbon source, was restricted to one species (Table 1); audouine (diguanidinopentane) was used as a carbon source by $P$. putida IRC204 (and not by the neotype strain ATCC 12633), homoarginine and succinylagmatine by $P$. cepacia NCTC 10743, guanidinopropionate by $P$. aeruginosa, creatinine by $P$. doudoroffii and carbamoylalanine by $P$. cepacia ATCC 17616.

\section{Urea excretion}

Since the excretion of urea is generally seen as a characteristic of Pseudomonas growing on guanidino and ureido compounds (Table 1) the spent culture liquors of the various strains were analysed to determine whether this metabolite had been excreted. Samples taken at the time of inoculation and at the time of harvesting were assayed for substrate consumption and urea excretion. All strains listed in Table 1 used urea as the sole nitrogen source. However, urea was not consumed when a $10 \mathrm{mM}$ ammonium salt was added to the growth medium, suggesting that urease was repressed by ammonium salts as described for $P$. aeruginosa by Jansen et al. (1980). The amount of urea excreted by Pseudomonas cells growing on guanidino and ureido compounds as sole carbon source was consequently a rough estimate of the amidinohydrolase activities involved in the release of urea. It also provided information concerning the pathway used for their utilization.

For instance, allantoic acid utilization by $P$. fluorescens and $P$. aeruginosa requires two (successive) hydrolases in the catabolic pathway (Trijbels \& Vogels, 1966 b) and we found $2 \mathrm{mols}$ of urea excreted per mol of substrate consumed (Table 1). On the other hand, in P. acidovorans only one amidinohydrolase is involved in allantoic acid degradation (Trijbels \& Vogels, 1966a) and we observed indeed that $1 \mathrm{~mol}$ of urea was produced per mol of substrate consumed. Consequently, except for $P$. indigofera which is unable to use allantoic acid, Pseudomonas belonging to groups I and II use this substrate via a reaction sequence identical to that described for $P$. aeruginosa and $P$. fluorescens.

In contrast, the $P$. putida strains excreted substantial amounts of urea from arginine. Analysis of arginine consumed and urea produced showed that 50 to $60 \%$ of the guanidino group of arginine was recovered as excreted urea. The explanation is that two pathways participate to the utilization of arginine as a carbon source, the arginine oxidase route in which urea is produced (Miller \& Rodwell, 1971; Stalon \& Mercenier, 1984 ) and the arginine succinyltransferase pathway in which it is not (Stalon et al., 1987).

\section{Catabolism of creatine and creatinine}

The catabolism of creatine and creatinine (Fig. 1) in $P$. doudoroffii is straightforward since $1 \mathrm{~mol}$ of urea is produced for each mol of substrate consumed (Table 1). 


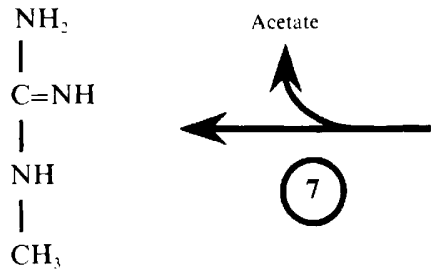<smiles>CN1CC(=O)NC1=N</smiles>

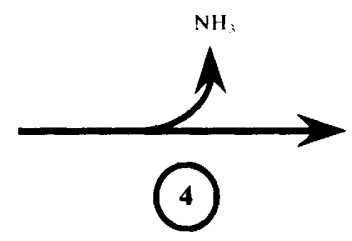

Methylguanidine

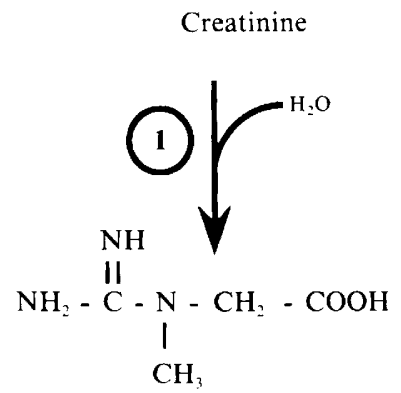<smiles>CN1CC(=O)NC1=O</smiles>
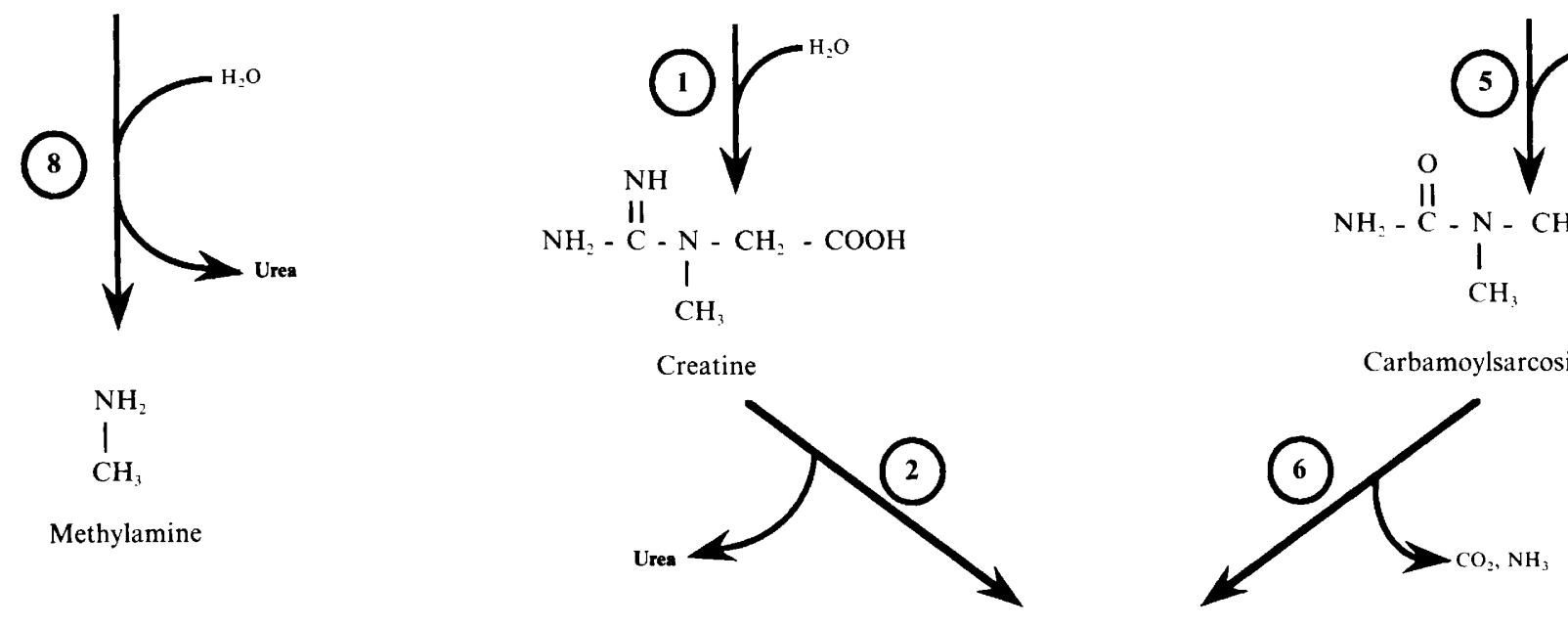

$\mathrm{CH}_{3}-\mathrm{NH}-\mathrm{CH}_{2}-\mathrm{COOH}$
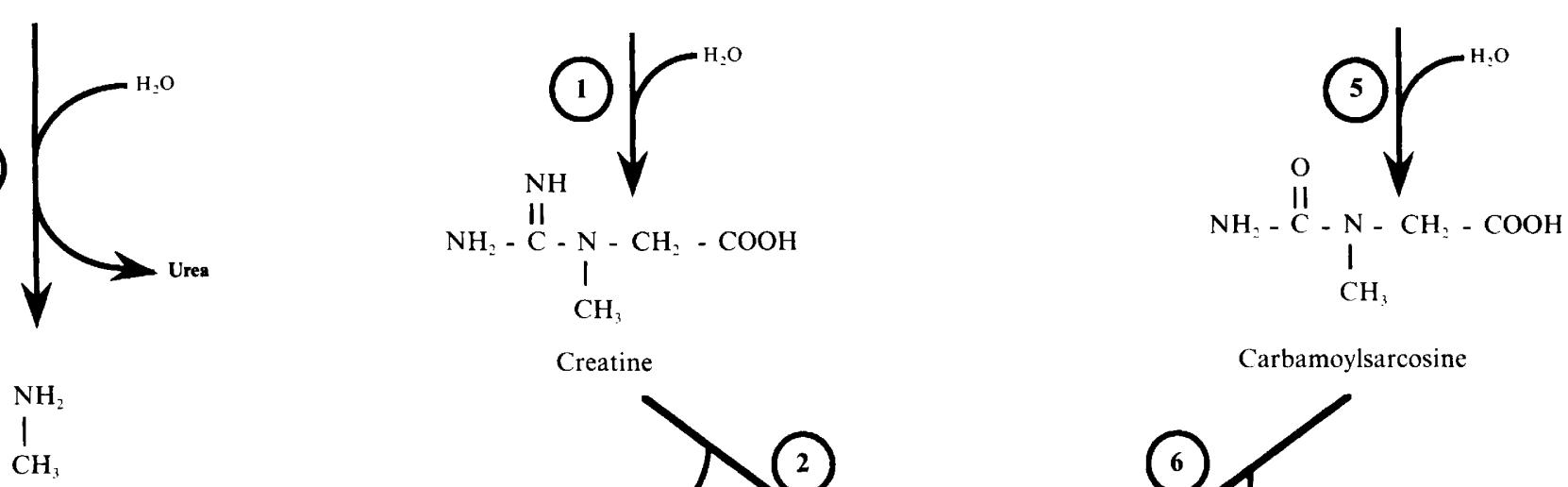

Methylamine

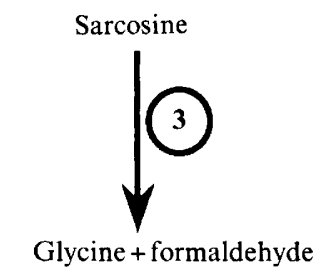

Fig. 1. Metabolic pathways of creatinine utilization by Pseudomonas. Enzymic steps. Numbers designate enzymes: 1, creatinine amidohydrolase (EC 3.5.2.10); 2, creatine amidinohydrolase (EC 3.5.3.3); 3, sarcosine dehydrogenase (EC 1.5.99.1); 4, creatinine deaminase (EC 3.5.4.21); 5, $\mathrm{N}$-methylhydantoinamidinohydrolase (EC 3.5.2.-); 6, carbamylsarcosine hydrolase (EC 3.5.3.-); 7, creatinine lyase (EC 4.1.3.-); 8, methylguanidine amidinohydrolase (EC 3.5.2.-).

Table 2. Creatine amidinohydrolase activity in $P$. doudoroffii and P. putida IRC204 grown in minimal medium 154

The growth substrates creatine and creatinine were used as the sole carbon source at $40 \mathrm{~mm}$, succinate at $20 \mathrm{mM}$; nitrogen sources were used at $10 \mathrm{~mm}$. Values are means from duplicate experiments.

\begin{tabular}{clcc}
\hline \hline Strain & $\begin{array}{c}\text { Addition to } \\
\text { minimal medium }\end{array}$ & $\begin{array}{c}\text { Doubling } \\
\text { time } \\
\text { (min) }\end{array}$ & $\begin{array}{c}\text { Creatine } \\
\text { amidinohydrolase } \\
\text { specific activity } \\
\text { [units (mg protein) }\end{array}$ \\
\hline P. doudoroffi & Succinate $+\mathrm{NH}_{4}^{+}$ & 80 & $0 \cdot 6$ \\
ATCC 27123 & Creatine & 97 & 77.0 \\
& Creatinine & 95 & 52.0 \\
P. putida & Succinate $+\mathrm{NH}_{4}^{+}$ & 55 & $0 \cdot 1$ \\
IRC204 & Creatine & 125 & 17.0 \\
& Succinate + creatine & 50 & $8 \cdot 0$ \\
& Succinate + creatinine & 120 & 1.0 \\
\hline
\end{tabular}


Table 3. Enzymes of arcaine and agmatine utilization in P. cepacia NCTC 10743

Cells were grown in medium 154 supplemented with $20 \mathrm{~mm}$ substrate when used as the sole carbon source and $10 \mathrm{mM}$ when used as sole nitrogen source (in the presence of $20 \mathrm{~mm}$-succinate). Enzyme assays were done in duplicate from two independently grown cultures. NT, Not tested.

\begin{tabular}{|c|c|c|c|c|c|}
\hline \multirow[b]{2}{*}{ Growth substrates } & \multicolumn{5}{|c|}{ Enzymes specific activity [units (mg protein) $)^{-1}$ ] } \\
\hline & $\begin{array}{l}\text { Generation } \\
\text { time (min) }\end{array}$ & $\begin{array}{l}\text { Arcaine- } \\
\text { amidino- } \\
\text { hydrolase }\end{array}$ & $\begin{array}{l}\text { Agmatine } \\
\text { amidino- } \\
\text { hydrolase }\end{array}$ & $\begin{array}{c}\text { Agmatine } \\
\text { dehydrogenase }\end{array}$ & $\begin{array}{l}\text { Guanidinobutyrate } \\
\text { amidinohydrolase }\end{array}$ \\
\hline Succinate $+\mathrm{NH}_{4}^{+}$ & 102 & $<0 \cdot 1$ & $<0.05$ & $<0 \cdot 1$ & $<0 \cdot 1$ \\
\hline Arcaine & 195 & 17.0 & 0.9 & $2 \cdot 5$ & $14 \cdot 0$ \\
\hline Agmatine & 90 & 0.35 & $0 \cdot 2$ & $5 \cdot 0$ & $18 \cdot 5$ \\
\hline Succinylagmatine & 115 & NT & 0.5 & 3.0 & $16 \cdot 0$ \\
\hline Succinate + agmatine & 60 & $<0.1$ & 0.1 & $2 \cdot 3$ & $10 \cdot 3$ \\
\hline Guanidinobutyrate & 60 & $<0 \cdot 1$ & $0 \cdot 1$ & $<0.1$ & $45 \cdot 0$ \\
\hline Guanidinovalerate & 75 & NT & 0.12 & $<0.1$ & $7 \cdot 0$ \\
\hline Homoarginine & 175 & $13 \cdot 5$ & $0 \cdot 32$ & $<0.1$ & $<0.1$ \\
\hline
\end{tabular}

Growth of $P$. doudoroffii at the expense of creatine or creatinine resulted in a fully induced level of creatine amidinohydrolase (EC 3.5.3.-; Table 2), suggesting that creatine is an intermediate in the degradation of creatinine by $P$. doudoroffi as found in other pseudomonads (Appleyard \& Woods, 1956; Rikitake et al., 1979).

The utilization of creatine as the sole carbon source by $P$. putida was characterized by the conversion of $50 \%$ of the guanidino group into excreted urea (Table 1). Under the conditions used (Table 1), $10 \mathrm{~mm}$-ammonium was present in the growth medium and no urease activity could be detected in cell extracts. Therefore, as in the case of arginine utilization where a fraction only of the amino acid was recovered as urea (Table 1), a second catabolic pathway was contributing to creatine utilization in $P$. putida.

Creatinine $(40 \mathrm{~mm})$ supported some growth of $P$. putida; however, the maximum cell yield corresponded to $25 \%$ of that obtained with the same concentration of creatine. Creatinine and creatine are in equilibrium in aqueous solution (Rikitake et al., 1979) and, indeed, our creatinine medium was found to contain at least $6 \mathrm{~mm}$ creatine suggesting that the growth of $P$. putida on creatinine resulted from the spontaneous conversion of creatinine to creatine in the medium. Addition of creatinine to succinate medium allowed $P$. putida cells to grow; however, extracts of these cells contained a lower creatine amidinohydrolase activity than cells grown with creatine as sole nitrogen source (Table 2). This low induced level of creatine amidinohydrolase was sufficient to account for growth on creatine formed at a limiting rate from creatinine by enzymic or non-enzymic conversion. Since creatine and creatinine are in equilibrium in aqueous solution, creatine utilization may also involve creatinine as an intermediate. A creatinine degradative pathway was described in a $P$. putida by
Yamada et al. (1975). It involves $N$-methylhydantoin- $N$ carbamoylsarcosine and sarcosine as intermediates.

Another possibility for creatine degradation could be the formation of methylguanidine and acetate followed by the release of urea from methylguanidine, as found in P. stutzeri (Van Eyck et al., 1968). The two Pseudomonas strains used in this study were unable to grow on methylhydantoin or methylguanidine as the sole carbon and nitrogen source. In addition, the methylguanidine pathway appears unlikely for creatine utilization since no methylguanidine could be identified as an excretion product during creatine or creatinine utilization of $P$. putida IRC204; besides, in vivo the metabolism of methylguanidine would produce urea. One mol of urea would consequently be formed per mol of creatine used. The lack of growth on a potential intermediate such as methylhydantoin does not, however, conclusively eliminate carbamoylsarcosine as an intermediate of creatine utilization of $P$. putida IRC204. For example, in a previous study it has been shown that succinylarginine, the first intermediate involved in the aerobic degradation of arginine by Pseudomonas cepacia (Vander Wauven \& Stalon, 1985) and P. aeruginosa (Jann et al., 1988 ) is not taken up by the cells.

\section{Agmatine utilization}

Until recently, the accepted physiologically important pathway for agmatine utilization in Pseudomonas was that catalysed by agmatine deiminase giving rise to carbamoylputrescine with the concomitant formation of ammonia (Stalon \& Mercenier, 1984; see Fig. 2). $P$. aureofaciens, $P$. doudoroffii and $P$. species P1855-344, not previously tested, also have an inducible agmatine deiminase activity (data not shown) and we therefore tentatively include the two latter species in Group I 


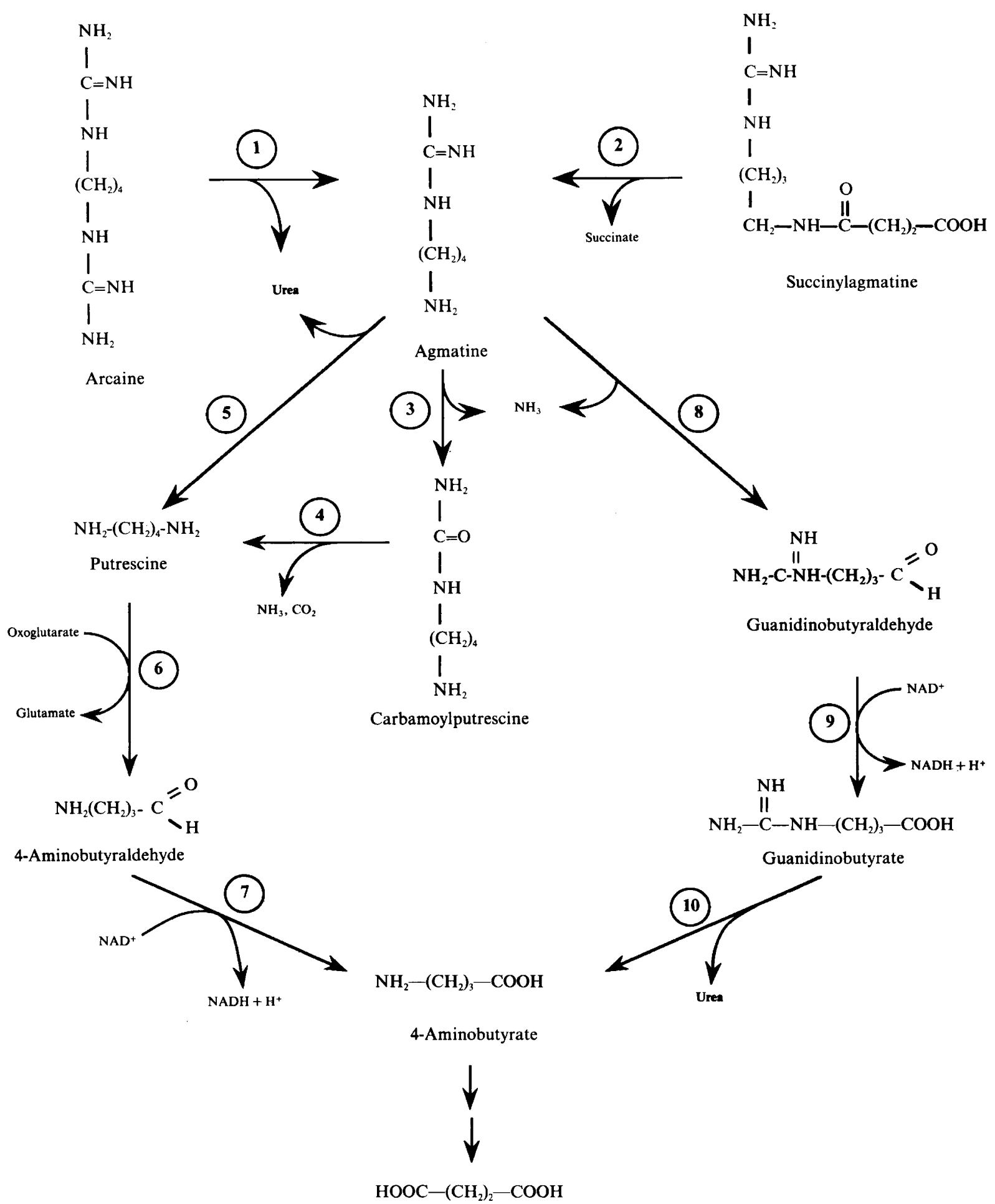

Succinate

Fig. 2. Pathways of agmatine catabolism in Pseudomonas. Enzymic steps. Numbers designate enzymes: 1, arcainase (arcaine amidinohydrolase) (EC 3.5.3.-); 2, succinylagmatine desuccinylase (EC 3.5.1.-); 3, agmatine deiminase (EC 3.5.3.12); 4, carbamoylputrescine hydrolase (EC 3.5.3.-); 5, agmatinase (agmatine amidinohydrolase) (EC 3.5.3.11); 6, putrescine transaminase (EC 2.6.1.-); 7, 4-aminobutyraldehyde dehydrogenase (EC 1.2.1.19); 8, agmatine dehydrogenase (EC 1.4.99.-); 9, 4-guanidinobutyraldehyde oxidoreductase (EC 1.2.1.-); 10, guanidinobutyrase (guanidinobutyrate amidinohydrolase) (EC 3.5.3.7). 
Pseudomonas as defined by Palleroni et al. (1974). By contrast, $\boldsymbol{P}$. cepacia belonging to group II as well as $\boldsymbol{P}$. indigofera, produce urea from agmatine (Table 1).

Resting cells of $P$. indigofera incubated with $10 \mathrm{~mm}$ agmatine and $10 \mathrm{~mm}$-aminooxyacetic acid, an inhibitor of pyridoxal phosphate enzymes involved in transamination, accumulated putrescine. Agmatine amidinohydrolase activity was induced 40 -fold by growing the cells on agmatine as compared to succinate plus ammonium medium [specific activity 3.5 units (mg protein $)^{-1}$. Maximum activity was observed at $\mathrm{pH} 9.5$ in $100 \mathrm{~mm}$-glycine/ $\mathrm{NaOH}$ buffer in the presence of $2 \mathrm{mM}$ $\mathrm{MnCl}_{2}$ and the apparent $K_{\mathrm{m}}$ for agmatine was $0.8 \mathrm{mM}$. Utilization of agmatine by $P$. indigofera appears to proceed by the pathway found in the Enterobacteriaceae (Friedrich \& Magasanik, 1979).

Resting cells of $P$. cepacia NCTC 10743 grown on agmatine and incubated with $10 \mathrm{~mm}$-agmatine and $10 \mathrm{~mm}$-aminooxyacetic acid produced large amounts of putrescine and 4-aminobutyrate whereas extracts of agmatine-grown cells of $P$. cepacia produced only putrescine. These cell extracts contained a low level of agmatinase activity (Table 3 ). It is not clear whether the low agmatine amidinohydrolase activity found in cells grown on various guanidino compounds is due to a genuine agmatine amidinohydrolase enzyme or resulted from a non-specific activity of some other amidinohydrolases (see below). Moreover, agmatine-grown cells of $\boldsymbol{P}$. cepacia also contained an inducible guanidinobutyrate amidinohydrolase activity (Table 3 ). This indicated that as well as agmatinase, another pathway of agmatine utilization may be present, involving guanidinobutyrate as an intermediate. Possible biochemical explanations are oxidation or transamination of agmatine to produce guanidinobutyraldehyde, a precursor of guanidinobutyrate (Fig. 2). Transamination appeared unlikely since $P$. cepacia cells incubated with glutamate, agmatine and aminooxyacetic acid still produced putrescine, urea and 4-aminobutyrate. Agmatine-grown cells were found to contain a high level of agmatine dehydrogenase activity. The artificial electron acceptors PMS and INT were required to obtain enzyme activity in vitro. Addition of FAD, FMN, NAD or NADP did not stimulate the reaction. Maximal activity was observed in $100 \mathrm{mM}$-Tris/HCl buffer, $\mathrm{pH} 8.25$. The apparent Michaelis constant for agmatine was $8 \mathrm{mM}$. No activity was detected in this extract with arginine, ornithine, putrescine or 4-aminobutyrate used as substrate instead of agmatine. Agmatine dehydrogenase and guanidinobutyrate amidinohydrolase specific activities in cells grown on different media are shown in Table 3. Agmatine and its precursors, arcaine and succinylagmatine, induced both activities whereas guanidinobutyrate induced guanidinobutyrate amidinohydrolase but not agmatine dehydrogenase. It therefore appears that $P$. cepacia has two agmatine degradative pathways. Mutations affecting these pathways are needed to assess the precise function of each pathway in this bacterium. Among the Pseudomonas spp. tested, only $P$. cepacia was able to use succinylagmatine. Urea excretion, agmatine dehydrogenase and guanidinobutyrate amidinohydrolase induction by succinylagmatine suggest that the first step in the utilization of this substrate involves agmatine formation. Cell-free extracts of bacteria grown on succinylagmatine catalyse the release of succinate from succinylagmatine. The specific activity of the desuccinylase measured in $50 \mathrm{~mm}-\mathrm{HEPES} / \mathrm{NaOH}$ buffer, $\mathrm{pH} \mathrm{7.0}$, in the presence of $1 \mathrm{mM}-\mathrm{CoCl}_{2}$ and $10 \mathrm{~mm}$-succinylagmatine was 0.9 units $(\mathrm{mg} \text { protein })^{-1}$. Cells grown on succinate contained no detectable succinylagmatine desuccinylase activity indicating that this activity is induced by the substrate present in the growth medium.

\section{Metabolism of arcaine, audouine, homoarginine and guanidinovalerate}

Arcaine (diguanidinobutane) could serve as the sole carbon and energy source for $P$. putida and $P$. cepacia (Tables 3 and 4). For $P$. aeruginosa, arcaine was a poor carbon source but an excellent nitrogen source (Table 4). Growth of either $P$. putida or $P$. aeruginosa in the presence of arcaine as the sole carbon source was accompanied by the excretion of $1 \mathrm{~mol}$ urea for each mol of substrate consumed. This suggests that arcaine utilization occurred through the action of an amidinohydrolase producing agmatine and urea. Cell-free extracts of $P$. putida, $P$. aeruginosa and $P$. cepacia catalysed the release of urea from arcaine. The arcaine amidinohydrolase of $P$. putida showed an absolute requirement for $\mathrm{Mn}^{2+}$. Maximum activity was observed at $\mathrm{pH} 9.5$ in $100 \mathrm{~mm}$-glycine/ $\mathrm{NaOH}$ buffer in the presence of $2 \mathrm{mM}$ $\mathrm{MnSO}_{4}$. In crude cell extract the apparent Michaelis constant for arcaine was $0.5 \mathrm{~mm}$. The composition of the growth medium significantly influenced the arcaine amidinohydrolase levels of $P$. putida (Table 4). Arcainegrown cultures were induced to a high level for arcaine amidinohydrolase and agmatine deiminase activities. Agmatine deiminase was induced to similarly high levels during growth on either agmatine or carbamoylputrescine whereas arcaine amidinohydrolase was repressed under these conditions (Table 4). Both enzymes were repressed in the presence of alternative good carbon and nitrogen sources. Arginine, guanidinobutyrate, guanidinoacetate, allantoate and creatine were not inducers of arcaine amidinohydrolase activity (data not shown). Extracts of arcaine- and audouine (diguanidinopentane)-grown cells contained high levels of both arcaine amidinohydrolase and audouine amidino- 
Table 4. Regulation of arcaine amidinohydrolase and agmatine deiminase synthesis in P. putida IRC204 and P. aeruginosa grown in medium 154

The growth substrates were used as the sole carbon source at $20 \mathrm{mM}$, nitrogen sources were used at $10 \mathrm{~mm}$. $P$. aeruginosa grown on arcaine was tested once. Other values are means of at least two determinations. Numbers in parantheses indicate audouine amidinohydrolase specific activity.

\begin{tabular}{|c|c|c|c|c|}
\hline \multirow[b]{2}{*}{ Strain } & \multirow[b]{2}{*}{ Growth substrates } & \multirow[b]{2}{*}{$\begin{array}{l}\text { Generation } \\
\text { time (min) }\end{array}$} & \multicolumn{2}{|c|}{$\begin{array}{c}\text { Specific enzyme } \\
\text { activity } \\
\left.\text { [Units (mg protein) })^{-1}\right]\end{array}$} \\
\hline & & & $\begin{array}{l}\text { Arcaine } \\
\text { amidino- } \\
\text { hydrolase }\end{array}$ & $\begin{array}{l}\text { Agmatine } \\
\text { deiminase }\end{array}$ \\
\hline \multirow{12}{*}{$\begin{array}{r}P . \text { putida } \\
\text { IRC204 }\end{array}$} & Citrate $+\mathbf{N H}_{4}^{+}$ & 54 & $<1 \quad(<1)$ & $<1$ \\
\hline & Arcaine & 126 & $60 \quad(24)$ & 8.9 \\
\hline & Audouine & 600 & $17.6(13.9)$ & $<1$ \\
\hline & Agmatine & 90 & $<1 \quad(<1)$ & $15 \cdot 2$ \\
\hline & Carbamylputrescine & 60 & $<1$ & 15 \\
\hline & Arcaine + agmatine & 54 & $5 \cdot 7$ & $11 \cdot 3$ \\
\hline & Arcaine + citrate & 90 & $8 \cdot 2$ & $6 \cdot 0$ \\
\hline & Arcaine + citrate $+\mathrm{NH}_{4}^{+}$ & 72 & 6 & 4 \\
\hline & Arcaine + citrate + glutamine & 54 & 4.9 & $2 \cdot 3$ \\
\hline & Arcaine + glutamine & 60 & $8 \cdot 6$ & $4 \cdot 2$ \\
\hline & Arcaine $+\mathrm{NH}_{4}^{+}$ & 120 & 50 & $9 \cdot 0$ \\
\hline & Arginine & 75 & $<1$ & $<1$ \\
\hline \multirow{4}{*}{$\begin{array}{l}\text { P. aeruginosa } \\
\text { PAO1 }\end{array}$} & Citrate $+\mathrm{NH}_{4}^{+}$ & 60 & $<1$ & $<1$ \\
\hline & Arcaine & $>1200$ & 3 & 49 \\
\hline & Agmatine & 72 & $<1$ & 30 \\
\hline & Citrate + arcaine & 280 & 1.6 & 18 \\
\hline
\end{tabular}

hydrolase activities. Arcaine amidinohydrolase activity of both cell extracts showed the same apparent Michaelis constant for arcaine. In the same way, audouine amidinohydrolase activity of both cell extracts showed the same apparent $K_{\mathrm{m}}$ value of $0.8 \mathrm{mM}$ for audouine and, in each case, corresponded to $40 \%$ of arcaine amidinohydrolase activity. These results suggested that the two activities could be due to the same enzyme. Support for such a bifunctional ureohydrolase came from the observation that the two activities could not be separated by usual protein fractionation methods, namely ammonium sulphate fractionation and molecular sieving, or by affinity chromatography on arginine Sepharose.

The production of $2 \mathrm{~mol}$ urea per mol of audouine consumed by $P$. putida cells suggested that, beside audouine amidinohydrolase activity which produces 1amidinocadaverine, another hydrolase was involved in the release of urea from this compound, or from the subsequent metabolites formed during audouine catabolism. Resting audouine-grown cells incubated with $10 \mathrm{~mm}$ each of audouine and aminooxyacetic acid produced cadaverine and traces of an unidentified guanidino compound. Prolonged incubation led to the disappearance of audouine and of the guanidino compound and to an increase of cadaverine formation. This suggested that amidinocadaverine (the presumed guanidino compound) and cadaverine were intermediates of audouine breakdown (Fig. 3). As amidinocadaverine was not available we were unable to determine whether cadaverine formation resulted from the action of two successive amidinchydrolases or of a single bifunctional enzyme.

During preparation of this manuscript, the properties of arcaine amidinohydrolase from the neotype $P$. putida strain ATCC 12633 were published by Yorifuji's group (Yorifuji et al., 1989). This strain can utilize diguanidino compounds with 3-10 methylene groups as the only nitrogen source. Partially purified preparations of arcaine amidinohydrolase from $\boldsymbol{P}$. putida IRC204 do not show any activity with diguanidinopropane. Arcaine amidinohydrolase from $P$. putida ATCC 12633 apparently has a broader specificity than that of strain IRC204.

Bifunctional amidinohydrolases are probably also present in $P$. cepacia where arcaine amidinohydrolase and homoarginine amidinohydrolase activities were coinduced (Table 3). These activities could not be separated by the usual protein fractionation procedures (data not shown). The homoarginine amidinohydrolase activity was $10-12 \%$ of the arcaine amidinohydrolase activity. Unlike the arcaine amidinohydrolase of $P$. putida, that of $P$. cepacia seemed to be devoid of audouine amidinohydrolase activity.

Amidinohydrolases with dual specificities have also been observed in the utilization of guanidinovalerate and 


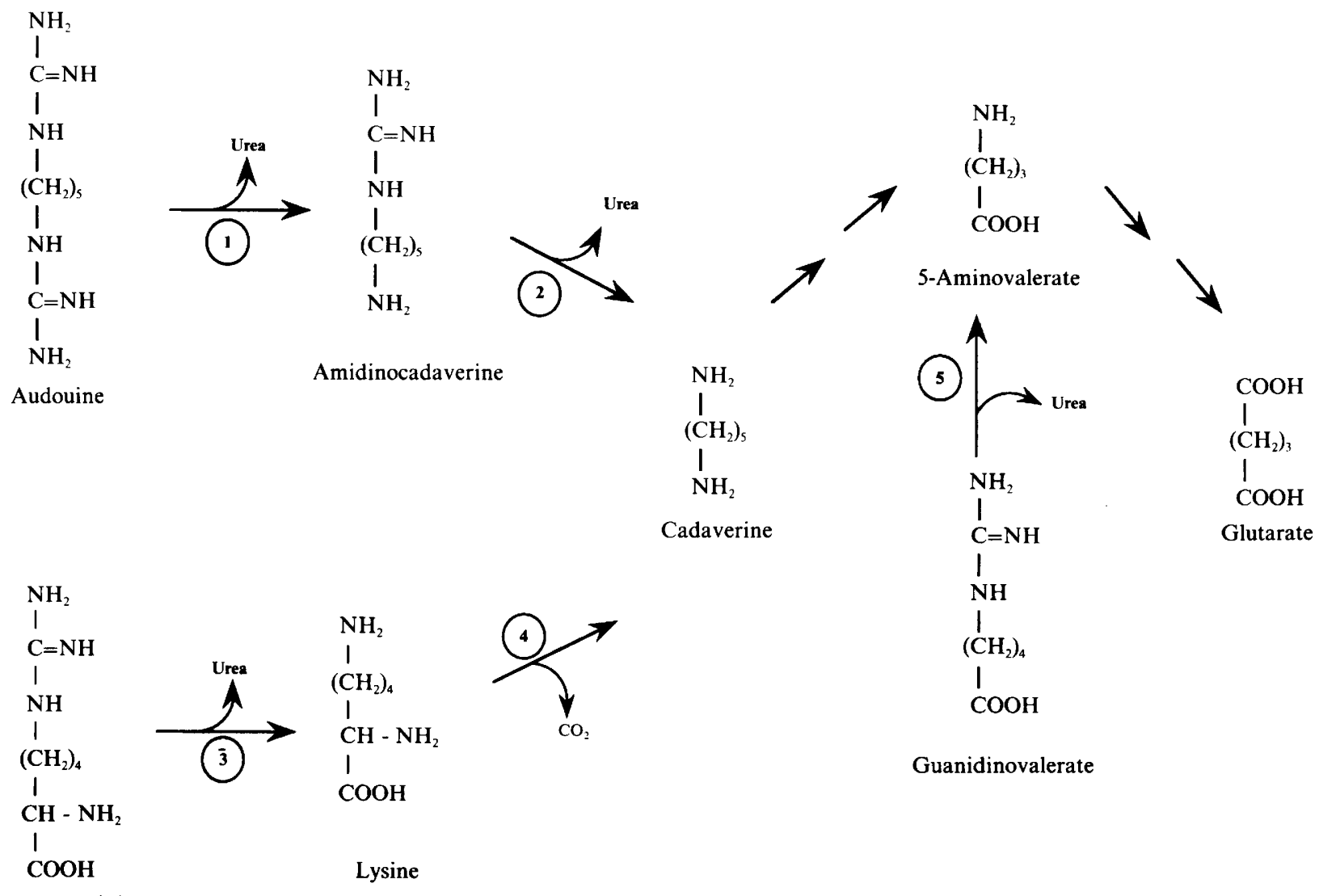

Homoarginine

Fig. 3. Catabolism of audouine, homoarginine and guanidinovalerate. Enzymic steps. Numbers designate enzymes: 1, audouinase (audouine amidinohydrolase) (EC 3.5.3.-); 2, amidinocadaverine amidinohydrolase (EC 3.5.3.-); 3, homoarginase (homoarginine amidinohydrolase) (EC 3.5.3.-); 4, lysine decarboxylase (EC 4.1.1.18); 5, guanidinovalerase (guanidinovalerate amidinohydrolase) (EC 3.5.3.-).

guanidinobutyrate (Figs 2 and 3). Guanidinovalerateand guanidinobutyrate amidinohydrolases activities from $P$. cepacia and $P$. doudoroffii showed the same apparent $K_{\mathrm{m}}$ values for guanidinobutyrate and guanidinovalerate ( $4 \mathrm{~mm}$ for $P$. cepacia amidinohydrolases and $11 \mathrm{~mm}$ for the $P$. douoroffii enzyme). However, this activity was tenfold higher with guanidinobutyrate than with guanidinovalerate. $P$. putida IRC204 utilizes guanidinovalerate as both a nitrogen and a carbon source, whereas $P$. putida ATCC 12633 uses it only as a nitrogen source. Concomitantly, with the guanidinobutyrate amidinohydrolase of $P$. putida IRC204, a guanidinovalerate amidinohydrolase activity representing no more than $2 \%$ of the former was also found.

\section{Discussion}

Biochemical diversity in metabolic pathways can provide a means of distinguishing between different groups of micro-organisms. We have observed that Pseudo- monas species, as a rule, employ only one of the possible agmatine catabolic pathways. This is, consequently, a biochemical character that may be of taxonomic value. It is interesting to note that the mode of agmatine utilization by species included in our study follows the ribosomal RNA/DNA homology groups delineated by Palleroni et al. (1974). All members of homology group I have the inducible agmatine deiminase route. Outside this group, alternative pathways function. Agmatinase is found in group II as represented by $P$. cepacia as well as in the unclassified species $P$. indigofera. However, more than one pathway can exist in one strain since in addition to agmatine amidinohydrolase activity, $P$. cepacia also possesses agmatine dehydrogenase activity.

Amidinohydrolase is the main activity used by Pseudomonas to degrade guanidino compounds since amidinohydrolases were characterized for audouine, arcaine, homoarginine, agmatine and guanidinovalerate beside the well known guanidinobutyrate- and guanidinopropionate amidinohydrolase activities (see Chou \& Rodwell, 1972; Yorifuji \& Shugai, 1978; Yorifuji et al., 1983). 
Guanidinopropionate and guanidinobutyrate amidinohydrolases from $P$. aeruginosa have been purified and characterized (Chou \& Rodwell, 1972; Yorifuji \& Shugai, 1978). These enzymes have been shown to share several molecular and catalytic properties and it has thus been suggested that they have evolved from a common ancestor (Yorifuji et al., 1983). It is interesting to observe that bifunctional amidinohydrolases apparently occur for the dissimilation of audouine and arcaine in P.putida, for arcaine and homoarginine in $P$. cepacia, and for guanidinovalerate and guanidinobutyrate in both $\boldsymbol{P}$. cepacia and $P$. doudoroffii. Arcaine amidinohydrolase from $P$. putida strain ATCC 12633 may have a broader specificity than the corresponding enzyme from $P$. putida IRC204 or P cepacia (Yorifuji et al., 1989). However, the hydrolysis of the amidino group to $\mathrm{CO}_{2}$ and ammonia is the chemical option used by Pseudomonas for the utilization of succinylarginine, whereas deamination is used for either arginine or agmatine.

The same diversity appears in the degradation of ureido compounds: ureohydrolysis is observed for allantoic acid and ureidoglycine; hydrolysis of the ureido group to $\mathrm{CO}_{2}$ and ammonia occurs for carbamoylputrescine (Mercenier et al., 1980; Stalon \& Mercenier, 1984), carbamoylalanine (Carvaca \& Grisolia, 1958; Campbell, 1960) and carbamoylsarcosine (Kim et al., 1976; Shimizu et al., 1986); phosphorolysis is observed for citrulline in Pseudomonas of group I having the arginine deiminase pathway and in other bacterial systems for carbamoylputrescine (Wargnies et al., 1979) and carbamoyloxamate (Vander Wauven et al., 1986).

This work was supported by grant 2.9003 .88 from the Belgian Fund for Joint Basic Research and by an 'Action de Recherche Concertée' financed by the Belgian Government. V.S. is a Research Associate of the National Fund for Scientific Research (Belgium).

\section{References}

Appleyard, G. \& Woods, D. D. (1956). The pathway of creatine catabolism by Pseudomonas ovalis. Journal of General Microbiology 14, 351-365.

ARCHIBALD, R. M. (1944). Determination of citrulline and allantoin and demonstration of citrulline in blood plasma. Journal of Biological Chemistry 156, 121-142.

CAMpBell, L. L. (1960). Reductive degradation of pyrimidine. V. Enzymatic conversion of $\mathrm{N}$-carbamyl- $\beta$-alanine to $\beta$-alanine, carbon dioxide and ammonia. Journal of Biological Chemistry 235, 23752378.

CarvaCa, J. \& GRISOlia, S. (1958). Enzymatic decarbamoylation of carbamyl $\beta$-alanine and carbamyl- $\beta$-aminoisobutyric acid. Journal of Biological Chemistry 231, 357-365.

CHOU, C. C. \& RoDwell, V. (1972). Metabolism of basic amino acids in Pseudomonas putida: guanidinobutyrate amido-hydrolase. Journal of Biochemistry 247, 4486-4490.
Cunin, R., Glansdorff, N., Piérard, A. \& Stalon, V. (1986). Biosynthesis and metabolism of arginine in bacteria. Microbiological Reviews 50, 314-352.

ENNOR, A. H. \& ATOKEN, L. A. (1948). The estimation of creatine. Biochemical Journal 42, 557-563.

Friedrich, B. \& MAGASANIK, B. (1979). Enzymes of agmatine degradation and the control of their synthesis in Klebsiella aerogenes. Journal of Bacteriology 137, 1127-1133.

Holloway, B. W. (1955). Genetic recombination in Pseudomonas aeruginosa. Journal of General Microbiology 13, 572-581.

JanN, A., Matsumoto, H. \& Hass, D. (1988). The fourth arginine catabolic pathway of Pseudomonas aeruginosa. Journal of General Microbiology 134, 1043-1053.

Jansen, D. B., Op Den Camp, H. J. M., Leenen, P. J. M. \& Vander DRIFT, C. (1980). The enzymes of ammonia assimilation in Pseudomonas aeruginosa. Archives of Microbiology 124, 197-203.

Kim, J. M., Shimizu, S. \& Yamada, H. (1986). Purification and characterization of a novel enzyme, $N$-carbamylsarcosine amidohydrolase from Pseudomonas putida P 77. Journal of Biological Chemistry 261, 11832-11839.

Meile, L. \& Leisinger, T. (1982). Purification and properties of the bifunctional proline dehydrogenase from Pseudomonas aeruginosa. European Journal of Biochemistry 129, 67-75.

Mercenier, A., Simon, J. P., HaAs, D. \& Stalon, V. (1980). Catabolism of L-arginine by Pseudomonas aeruginosa. Journal of General Microbiology 116, 381-389.

MICKLUS, J. M. \& STEIN, I. (1973). The colorimetric determination of mono and disubstituted guanidines. Analytical Biochemistry 54, 545553.

Miller, D. L. \& Rodwell, V. (1971). Metabolism of basic amino acids in Pseudomonas putida. Journal of Biological Chemistry 246, 5053-5058.

Palleroni, N. J., Kunisawa, R., Contopoulou, R. \& Doudoroff, M. (1974). Nucleic acid homologies in the genus Pseudomonas. International Journal of Systematic Bacteriology 23, 333-339.

PrescotT, L. M. \& Jones, M. E. (1969). Modified methods for determination of carbamylaspartate. Analytical Biochemistry 32, 408-419.

Rikitake, K., OKa, I., ANDo, M., Yoshimoto, T. \& Tsuru, D. (1979). Creatinine amidohydrolase from $P$. putida: purification and some properties. Journal of Biochemistry 96, 1104-1117.

SHIMIZU, S., KIM, J. M., SHINNEN, Y. \& Y AMADA, M. (1986). Evaluation of two alternative metabolic pathways for creatinine degradation in microorganisms. Archives of Microbiology 145, 322-328.

Stalon, V., Ramos, F., Piérard, A. \& Wiame, J. M. (1967). The occurrence of a catabolic and an anabolic ornithine carbamoyltransferase in Pseudomonas fluorescens. Biochimica et Biophysica Acta 139, 91-97.

StALON, V. \& MerCENIER, A. (1984). L-Arginine utilization by Pseudomonas species. Journal of General Microbiology 130, 69-76.

Stalon, V., Vander Wauven, C., Momin, P. \& Legrain, C. (1987). Catabolism of arginine, citrulline and ornithine by Pseudomonas and related bacteria. Journal of General Microbiology 133, 2487-2495.

TriJBels, F. \& Vogels, G. D. (1966a). Degradation of allantoin by Pseudomonas acidovorans. Biochimica et Biophysica Acta 113, 292301.

TriJbels, F. \& Vogels, G. D. (1966b). Allantoinase and ureidoglycolase in Pseudomonas and Penicillium species. Biochimica et Biophysica Acta 118, 387-395.

Vander Wauten, C. \& Stalon, V. (1985). Occurrence of succinyl derivatives in the catabolism of arginine in Pseudomonas cepacia. Journal of Bacteriology 164, 882-886.

VANDER Wauven, C., Simon, J. P., Slos, P. \& Stalon, V. (1986). Control of enzyme synthesis in the oxalurate catabolic pathway of Streptococcus faecalis ATCC 11700: evidence for the existence of a third carbamate kinase. Archives of Microbiology 145, 386-390.

Van Eyck, J. G., VermaAt, R. J., LeiJnse, H. J. \& LeiJnSe, B. (1968). The conversion of creatinine by creatininase of bacterial origin. Enzymologia 34, 199-202.

Wargnies, B., Lauwers, N. \& Stalon, V. (1979). Structure and properties of putrescine carbamoyltransferase of Streptococcus faecalis. European Journal of Biochemistry 101, 145-152. 
YorifuII, T. \& SUGAI, I. (1978). 3-Guanidinopropionate amidinohydrolase and 4-guanidinobutyrate amidinohydrolase of Pseudomonas aeruginosa strain PAO. Agricultural and Biological Chemistry 42, 1789-1790.

Yorifui, T., Kobayashi, T., Tabuchi, A., Shiratani, Y. \& Yonoha, K. (1983). Distribution of amidinohydrolase among Pseudomonas and comparative studies of some purified enzymes by one- dimensional peptide mapping. Agricultural and Biological Chemistry 47, 2825-2830.

Yorifuj, T., Kanoeke, M., Shimizu, E., Shiota, K. \& Matsuo, R. (1989). Degradation of $\alpha, \omega$ di-guanidinoalkanes and a novel enzyme, diguanidinobutane amidinohydrolase in P. putida. Agricultural and Biological Chemistry 53, 3003-3009. 